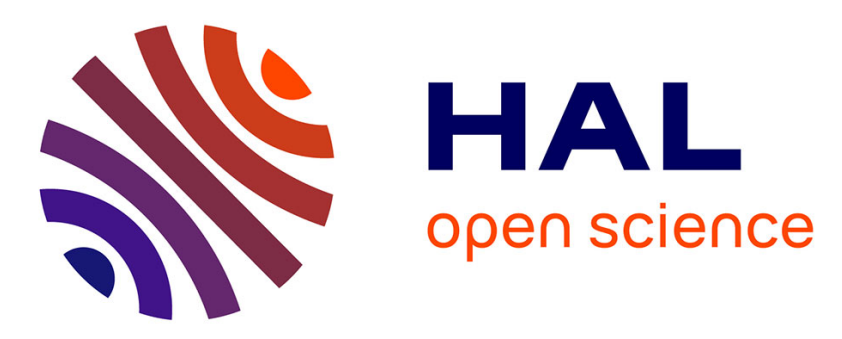

\title{
Crystalline-like structures and multilayering in Langmuir films of ionic liquids at the air-water interface
}

Eduardo. J. M. Filipe, Pedro Morgado, Miguel Teixeira, Karina Shimizu, Nathalie Bonatout, Michel Goldmann, José Nuno Canongia Lopes

\section{- To cite this version:}

Eduardo. J. M. Filipe, Pedro Morgado, Miguel Teixeira, Karina Shimizu, Nathalie Bonatout, et al.. Crystalline-like structures and multilayering in Langmuir films of ionic liquids at the air-water interface. Chemical Communications, 2016, 52 (32), pp.5585-5588. 10.1039/c6cc01368f . hal-01314512

\section{HAL Id: hal-01314512 \\ https://hal.sorbonne-universite.fr/hal-01314512}

Submitted on 11 May 2016

HAL is a multi-disciplinary open access archive for the deposit and dissemination of scientific research documents, whether they are published or not. The documents may come from teaching and research institutions in France or abroad, or from public or private research centers.
L'archive ouverte pluridisciplinaire HAL, est destinée au dépôt et à la diffusion de documents scientifiques de niveau recherche, publiés ou non, émanant des établissements d'enseignement et de recherche français ou étrangers, des laboratoires publics ou privés. 


\section{Crystalline-like structures and multilayering in Langmuir films of ionic liquids at the air-water interface}

Received 00th January 20xx Accepted 00th January 20xx

DOI: $10.1039 / \times 0 \times x 00000 x$
Eduardo. J. M. Filipe, ${ }^{a *}$ Pedro Morgado, ${ }^{a}$ Miguel Teixeira, ${ }^{a}$ Karina Shimizu, ${ }^{a}$ Nathalie Bonatout, ${ }^{b, c}$ Michel Goldmann ${ }^{b, d}$ and José Nuno Canongia Lopes ${ }^{a}$

www.rsc.org/

Langmuir films of $\left[\mathrm{C}_{18} \mathrm{mim}\right]\left[\mathrm{NTf}_{2}\right]$ ionic liquid exhibited, for the first time, the reversible formation of crystalline-like structures at the surface of water, compatible with the formation of multilayers. Atomistic molecular dynamics simulation results support the experimental findings, unambiguously indicating the existence of a trilayer.

Ionic liquids (ILs) are organic salts with unusually low melting temperatures. Their liquid structure results from a complex interplay between electrostatic, van der Waals and hydrogenbond interactions, known to impose mesoscopic organization in the bulk fluid. ILs are thus recognized as nano-structured fluids, in which a polar network (formed by the charged moieties of the ions) is permeated by more or less extensive non-polar domains (composed by alkyl side chains or other non-polar residues of the molecular ions), in some cases forming two continuous sub-phases. The meso-structuration of ILs has been analysed using different techniques, from x-ray diffraction experiments ${ }^{1}$ to molecular dynamics modelling (MD). ${ }^{2}$

Some of the potential applications of ILs involve processes that take place at interfaces, either at their own liquid-vapour interface or when adsorbed at the surface of solids. The study of the interfacial properties of ILs, pure or in solution, is therefore of utmost importance. It should also be realised that ILs with long alkyl side chains have molecular structures that closely resemble those of typical ionic surfactants and thus are able to display amphiphilic behaviour, forming self-assembled structures such as micelles or liquid crystals. Surprisingly, the behaviour of ILs at the surface of water and in particular the possibility of forming monolayers at the air/water interface has been little investigated.

\footnotetext{
a. Centro de Química Estrutural, Instituto Superior Técnico, Universidade de Lisboa, 1049-001 Lisboa, Portugal. E-mail: efilipe@tecnico.ulisboa.pt

borbonne Universités, UPMC Univ Paris 06, CNRS-UMR 7588, Institut des NanoSciences de Paris, F-75005, Paris, France.

c. Laboratoire des Interfaces Complexes et de l'Organisation Nanométrique ECE Paris, Ecole d'Ingénieurs (France).

${ }^{d .}$ Synchrotron SOLEIL L'Orme des Merisiers Saint-Aubin - BP48 91192 Gif/Yvette Cedex France.
}

A better understanding of the behavior of ILs at liquid interfaces can, in our opinion, be obtained studying the formation of thin films through the Langmuir technique. To date this is a largely unexplored field: Bai et al. ${ }^{3}$ reported the synthesis of gold nanoplates using monolayers of 1-hexadecyl3-methylimidazolium bromide, $\left[\mathrm{C}_{16} \mathrm{mim}\right] \mathrm{Br}$ as templates. However, very little was reported about the IL films, apart from being highly unstable unless $\mathrm{HAuCl}_{4}$ was dissolved in the aqueous sub-phase. Mukherjee et al. $^{4}$ reported a study on the general interfacial behavior of trihexyl (tetradecyl) phosphonium bis-2,4,4-(trimethylpentyl) phosphinate,

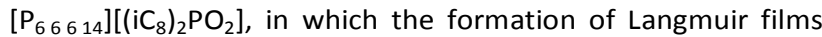
was briefly addressed. Ye et al. used the LB technique to prepare supported ILs catalysts. ${ }^{5}$ Very recently the behavior of the $\left[\mathrm{P}_{66614}\right]^{+}$cation was again studied, combined with bis(trifluoromethylsulfonyl)imide, $\left[\mathrm{NTf}_{2}\right]^{-}$, and dicyanamide, $\left[\mathrm{N}(\mathrm{CN})_{2}\right]^{-}$, anions. ${ }^{6}$ Both surfactants form expanded liquid-like films of low stability: that of $\left[\begin{array}{llll}P_{6} & 6 & 6 & 14\end{array}\right]\left[\mathrm{NTf}_{2}\right]$ collapses at relatively low surface pressure $\left(\sim 12 \mathrm{mNm}^{-1}\right)$, while the higher solubility of the $\left[\mathrm{P}_{66614}\right]\left[\mathrm{N}(\mathrm{CN})_{2}\right]$ in water is responsible for a film of very low cohesion. On a slightly different topic, the structure of Langmuir films at the surface of liquid mercury for $\mathrm{N}$-butyl-N-methylpyrrolidinium tris(pentafluoroethyl) trifluorophosphate, $\left[\mathrm{C}_{4} \mathrm{C}_{1}\right.$ pyrr][FAP], was inferred from $\mathrm{x}$-ray reflectivity by Tamam et $a l^{7}$ This is thus one of the first comprehensive studies focusing on the formation of Langmuir films of a common water-immiscible ionic liquid at the airwater interface.

In this work we have studied the behaviour of the waterimmiscible ionic liquid 1-methyl-3-octadecylimidazolium bis(trifluoromethylsulfonyl)imide, $\left[\mathrm{C}_{18} \mathrm{mim}\right]\left[\mathrm{NTf}_{2}\right]$, at the air-water interface. The results indicate that on compression, $\left[\mathrm{C}_{18} \mathrm{mim}\right]\left[\mathrm{NTf}_{2}\right]$ reversibly forms multilayers at the surface of water, which can be observed as crystalline structures by Brewster Angle Microscopy (BAM). The interpretation of the results is further supported by molecular dynamics simulation results. To the best of our knowledge, this is the first time that such structures have been observed and reported. 


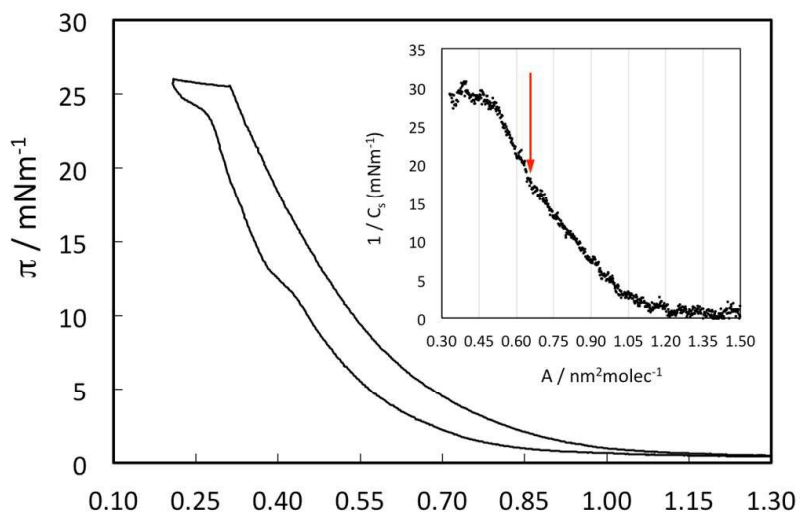

A / nm² molec $^{-1}$

Fig. 2 Surface pressure $(\pi)$ versus area per molecule $(A)$ isotherm of [C18mim] [NTf2] at the surface of water at $298 \mathrm{~K}$.

The pressure versus area isotherm representing a compression / expansion cycle of $\left[\mathrm{C}_{18} \mathrm{mim}\right]\left[\mathrm{NTf}_{2}\right]$ at the surface of water at $298 \mathrm{~K}$ is shown in figure 1 . On compression $\left[\mathrm{C}_{18} \mathrm{mim}\right]\left[\mathrm{NTf}_{2}\right]$ displays a gradual increase of surface pressure over a relatively long range of areas per molecule (1.3 to 0.3 $\mathrm{nm}^{2} \mathrm{molec}^{-1}$ ), followed by a region of very high compressibility, as shown by a nearly constant surface pressure plateau, between 0.3 and $0.1 \mathrm{~nm}^{2}$ molec $^{-1}$. On expansion the system displays large hysteresis: the whole isotherm is shifted to smaller surface areas/pressures and the plateau is replaced by a region in which the surface pressure decreases continuously at different intermediate rates.

A more detailed analysis of the compression isotherm reveals a number of additional observations:

1) The area per molecule when the surface pressure starts to increase (lift-off) is of the order of $1.5 \mathrm{~nm}^{2} \mathrm{molec}^{-1}$. This is much smaller than the areas obtained from the energyoptimized configurations of the $\left[\mathrm{C}_{18} \mathrm{mim}\right]^{+}$and $\left[\mathrm{NTf}_{2}\right]^{-}$ions ( $\left.2.1 \mathrm{~nm}^{2} \mathrm{molec}^{-1}\right)$. Thus, the isotherm provides no evidence of a state in which the ions lay flat at the surface of water.

2) Areas of the order of $0.8-0.7 \mathrm{~nm}^{2}$ molec $^{-1}$ are consistent with a monolayer of $\left[\mathrm{NTf}_{2}\right]^{-}$anions and $\left[\mathrm{C}_{18} \mathrm{mim}\right]^{+}$cations, in which the plane of the imidazolium ring lays parallel to the surface of water and the alkyl side chains protrude in a direction normal to it. This type of organization can be found in crystals of long-chained 1-alkyl-3-methylimmidazolium ions with different anions, including $\left[\mathrm{NTf}_{2}\right]^{-8}$. It is thus reasonable to admit that during compression, the film goes through a state in which a continuous monolayer of the charged moieties of the $\left[\mathrm{C}_{18} \mathrm{mim}\right]^{+}$and $\left[\mathrm{NTf}_{2}\right]^{-}$ions is formed.

3) The inset of figure 1 displays the inverse compressional modulus, $1 / C_{S}=-A(\partial \pi / \partial A)$, along compression, between 1.5 to $0.3 \mathrm{~nm}^{2} \mathrm{molec}^{-1}$. As can be seen, the slope visibly changes to a higher value at around $0.65 \mathrm{~nm}^{2}$ molec $^{-1}$. This is a clear indication that at this area the film undergoes a change to a different compression regime.

4) Further compression of the film produces a gradual increase in surface density up to $0.33 \mathrm{~nm}^{2} \mathrm{molec}^{-1}$, the beginning of the plateau at a surface pressure of $25.9 \mathrm{mNm}^{-1}$.
These results indicate that the monolayer can be considerably compressed, possibly corresponding to a change of orientation of imidazolium rings and to some degree of stratification of the film. These relatively high surface densities are similar from those found at the free surface of liquid $\left[\mathrm{C}_{n}\right.$ mim] $\left[\mathrm{NTf}_{2}\right] \mathrm{ILs}^{9}$

At $25.9 \mathrm{~m} \mathrm{Nm}^{-1}$ and $0.33 \mathrm{~nm}^{2}$ molec $^{-1}$ a highly compressible region is reached (plateau) that persists until a surface density of around $0.11 \mathrm{~nm}^{2} \mathrm{molec}^{-1}$. These small areas per molecule are not compatible with a monolayer. Compression along the plateau is thus only consistent with the development of multilayered structures.

It should be kept in mind that the surface tension resulting from a layer of ionic liquid at the air-water interface with the alkyl chains oriented towards the air should be much lower, and therefore more stable, than the opposite. This is supported by the evidence that at the air-IL interface alkyl side chains are oriented towards air. ${ }^{9}$ Moreover, the surface tension along different homologous series of ILs (including the $\left[\mathrm{C}_{n} \mathrm{mim}\right]\left[\mathrm{NTf}_{2}\right]$ family) decreases with the increase of the alkyl chains length approaching the surface tension of liquid alkanes. ${ }^{10}$ Thus, the formation of monolayers or trilayers should be preferred relatively to bilayers or tetralayers, since the later correspond to arrangements in which ions would be directly exposed to the gas phase.

These interpretations are supported and complemented by BAM images obtained along the compression / expansion cycle (figure 2). As can be observed, at very large areas during compression the images show the existence of circular domains resembling a two dimensional (2D) foam. These are generally interpreted as an evidence of a state of $2 D$ liquidvapour equilibrium, i.e., monolayer domains in equilibrium with monomers dispersed throughout the surface of water. For smaller areas the domains gradually merge, forming a

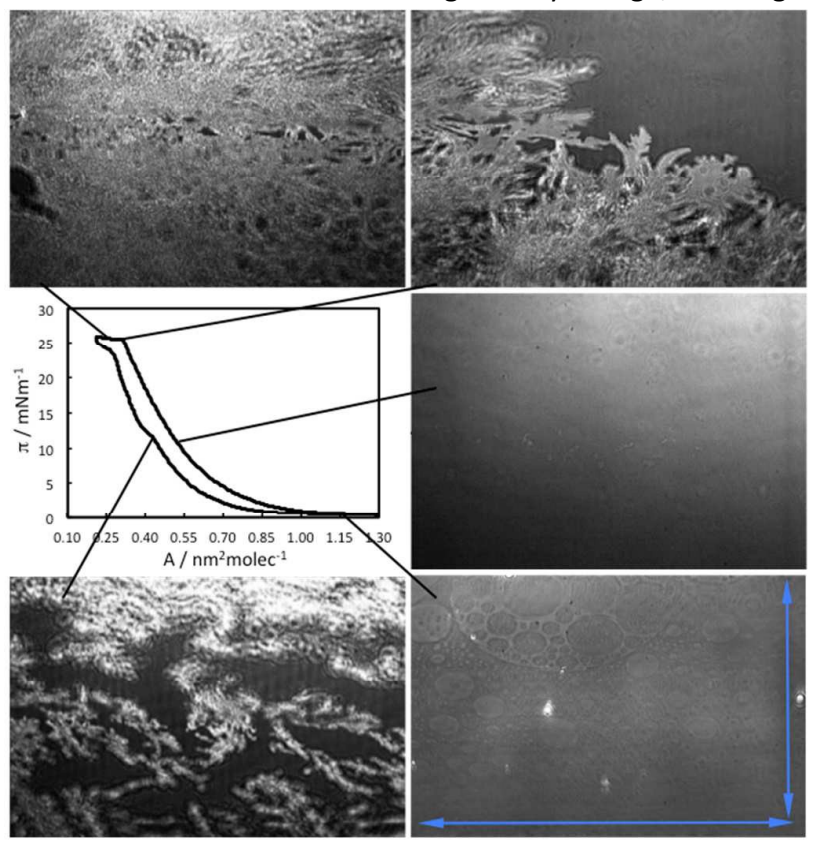

Fig. 1 Brewster Angle Microscopy images of [C18mim][NTf2] at the surface of water at $298 \mathrm{~K}$, along the compression / expansion cycle. 
continuous "compressed monolayer". As the plateau is reached around $0.3 \mathrm{~nm}^{2}$ molec $^{-1}$ crystalline structures start to be visible, associated to an increase of the reflected intensity, indicating a thicker film. On compression, the structures gradually occupy larger areas of the surface until the end of the plateau. During expansion, the crystalline structures seem to gradually "dissolve" until the liquid domains are recovered.

At large areas, the observed foam confirms that the IL ion pairs, instead of forming a homogeneous film, spontaneously condense forming domains even at very low density. When compressed, these expanded liquid domains coalesce forming a homogeneous film. As the film is further compressed from an expanded monolayer to a "compressed monolayer" new domains can be observed in the BAM images. Finally, along the plateau the observed crystalline structures can be assigned to the formation of multilayers.

In order to obtain a molecular level insight into the experimental macroscopic results, molecular dynamics simulations have been performed. Given the complexity of the system, the purpose of the simulations is to gather structural arguments that support the proposed interpretations, rather than quantitative confirmation of the experimental results.

Molecular dynamics runs at $298 \mathrm{~K}$ were carried out using the DL_POLY package. ${ }^{11}$ Water and all ionic liquids were modeled using, respectively, the SPC model ${ }^{12}$ and a previously described all-atom force field (CL\&P), ${ }^{13}$ based on the OPLS-AA framework $^{14}$ but developed specifically to encompass entire ionic liquid families like $\left[\mathrm{C}_{n} \mathrm{mim}\right]\left[\mathrm{NTf}_{2}\right]$.

The boxes were equilibrated under isothermal ensemble conditions for $1 \mathrm{~ns}$ at $298 \mathrm{~K}$ and $1 \mathrm{~atm}$ using the Nosé-Hoover thermostat with time constants of $0.5 \mathrm{ps}$. Several (at least ten) consecutive simulation runs of $1 \mathrm{~ns}$ each were used to produce equilibrated systems at the studied temperature. Electrostatic interactions were treated using the Ewald summation method considering six reciprocal-space vectors, and repulsive-dispersive interactions were explicitly calculated
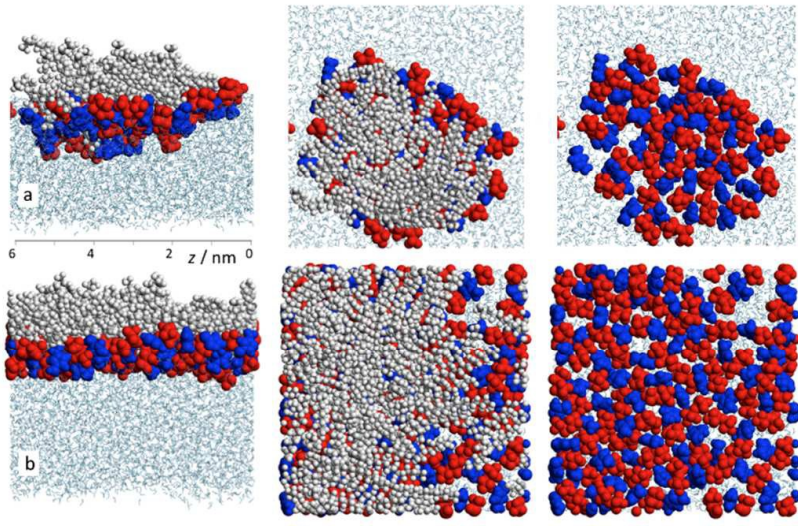

Fig. 3 Snapshots of the simulation box for systems with $1.42 \mathrm{~nm}^{2}$ molec$^{-1}$ (top row, a) and $0.62 \mathrm{~nm}^{2}$ molec $^{-1}$ (bottom row, b) surface density. The left column shows views perpendicular to the surface; the central and right columns show views from the top of the surface with and without the representation of the alkyl side chains of the IL, respectively. Water molecules are depicted as cyan stick hedges; IL anions as red spacefilled structures; imidazolium rings of the IL cations as blue space-filled clusters; alkyl side chains of the IL cations as gray/white space-filled atoms. below a cutoff distance of $1.6 \mathrm{~nm}$.

The simulation boxes consisted of 2400-4000 water molecules forming $2.5-4.0 \mathrm{~nm}$ thin films of liquid in the $x, y$ plane. The height of the box was at least 5 times the thickness of the water film, which was equilibrated before a given number of ion pairs were added to the system. These were inserted either using random ion-pair configurations directly added to the vacuum sub-phase or using the Packmol software $^{15}$. The number of added ion pairs and/or the side length of the simulation box were adjusted to obtain the desired surface density. Simulation runs were performed at average surface densities of $1.42,0.62,0.48,0.33$ and 0.24 $\mathrm{nm}^{2}$ molec $^{-1}$.

Figure 3 shows snapshots of different perspectives of the simulation boxes obtained at $1.42 \mathrm{~nm}^{2}$ molec $^{-1}$ and $0.62 \mathrm{~nm}^{2}$ molec $^{-1}$. As can be seen, at $1.42 \mathrm{~nm}^{2}$ molec $^{-1}$ the surface of water is not completely covered. The ions have clustered together forming a "drop" of IL "floating" on the surface of water. The alkyl chains are not in contact with water and are visibly liquid-like disordered. The $\mathrm{NTf}_{2}^{-}$ions and the charged parts of the $\mathrm{C}_{18} \mathrm{mim}^{+}$cations form a layer in contact with water, in which a checkerboard arrangement of the ions is clearly visible. The film is probably in a state of vapourexpanded liquid equilibrium, although isolated ion pairs at the surface of water are very rare. The real surface density within the unconstrained cluster of ions is of the order of $0.60-0.70$ $\mathrm{nm}^{2}$ molec $^{-1}$ and is controlled by the balance of Coulomb forces between the charged groups. Within the layer of alkyl chains the density is visibly very low and consequently the chains are unable to organize vertically. At $0.62 \mathrm{~nm}^{2}$ molec $^{-1}$ the surface of water is almost completely covered by IL. Again, the charged groups form a layer in contact with water in an alternated distribution, while the alkyl chains form an expanded liquid-like layer in contact with the vapour phase. It is interesting to note that the alkyl layer is not able to cover completely the underlying charged layer of ions (Figure $3 b$,

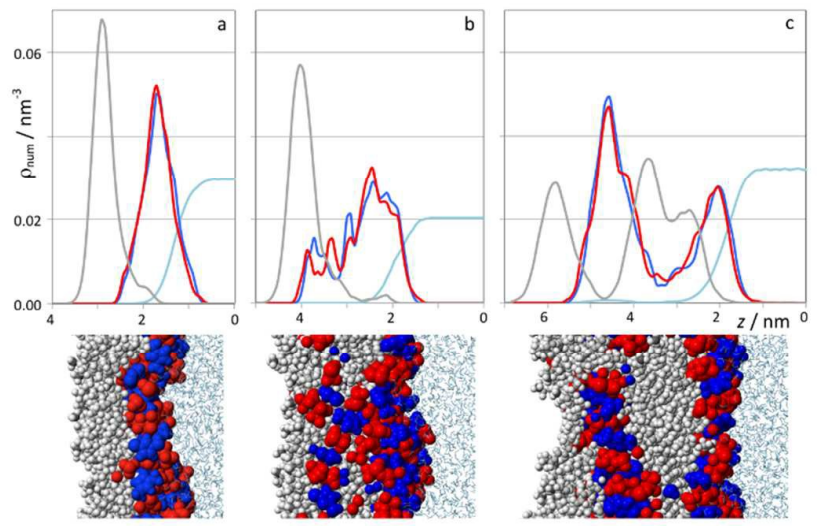

central column).

Fig. 4 Numerical density distribution functions, $\rho_{\text {num }}$, along the direction normal to the surfaces, $z$, for three selected atom types in $\left[\mathrm{C}_{18}\right.$ mim] $\left[\mathrm{NTf}_{2}\right]$ obtained at $0.48 \mathrm{~nm}^{2}$ molec ${ }^{1}, 0.33 \mathrm{~nm}^{2}$ molec $^{-1}$ and $0.24 \mathrm{~nm}^{2}$ molec $^{-1}$. Terminal carbon atoms of the alkyl side chain of the cation, $\mathrm{CT}$, as gray lines; nitrogen atom of the anion as red lines; imidazolium ring centroid, im, as blue lines; water molecules as cyan lines. The bottom row shows matching simulation snapshots represented with the same length scale of the top row and the same color-coding of Figure 3. 
Figure 4 shows number density profiles along the $z$-axis obtained at $0.48 \mathrm{~nm}^{2}$ molec $^{-1}, 0.33 \mathrm{~nm}^{2}$ molec $^{-1}$ and $0.24 \mathrm{~nm}^{2}$ molec $^{-1}$ for four atom types: chain terminal carbon atom, CT; imidazolium ring centroid, $\mathrm{CR}$; nitrogen atom of the anion, NBT; oxygen atom of water, $\mathrm{O}$. The corresponding side views of the simulation boxes are also shown.

At $0.48 \mathrm{~nm}^{2}$ molec $^{-1}$ (figure 4 a), a relatively high surface density, a layer of alternating ions with the corresponding charged groups in contact with water can be observed as before. However, it is also clear that the ion pairs now distribute over a wider range of the direction normal to the surface, $z$, thus forming a thicker layer. Some of the ions occupy the "empty" spaces between the alkyl chains, increasing the average density and hence the cohesion of the layer. This observation explains the gradual formation of a "compressed monolayer" between $0.65 \mathrm{~nm}^{2}$ molec $^{-1}$ and the beginning of the plateau, at $0.35 \mathrm{~nm}^{2} \mathrm{molec}^{-1}$. Again, the alkyl chains form a layer in contact with the vapour phase, now denser and with less ion pairs exposed to the vapour. Nevertheless, the liquid-like organization of the chains is still apparent, as shown by the distribution of CT groups. CT groups well inside the layer of charged groups are readily visible.

The average surface density of $0.33 \mathrm{~nm}^{2}$ molec $^{-1}$ was also studied as being representative of the onset of the plateau (figure 4b). The profiles of both charged groups show a series of ill-defined peaks, corresponding to a visibly less organised state in which the groups now seem to be spread over a wider range of $z$. At this stage, compression of the monolayer seems to have expelled more ion pairs from the surface of water.

Finally, simulations were performed at an average surface density of $0.24 \mathrm{~nm}^{2} \mathrm{molec}^{-1}$, corresponding to a state at mid plateau. The results are shown in figure $4 c$, where the density profile, as well as the snapshot, unambiguously reveals the presence of a trilayer. As at low surface density, a first level of charged groups forms a layer of alternating ions in contact with water. The corresponding alkyl chains form a liquid-like layer extending in the $z$ direction and are in contact with the alkyl chains belonging to the ion pairs on the next layer. The charged groups of the middle and upper layers clearly form a double layer, again displaying a checkerboard configuration. A last layer of ion pairs completes the trilayer, structurally very similar to the monolayer observed at the surface of water at large surface areas (figure $4 \mathrm{~b}$ ). To some extent, the structure of the trilayer can be considered a combination of those observed at the interfaces of bulk pure IL with air and water.

In conclusion, the formation of Langmuir films of $\left[\mathrm{C}_{18} \mathrm{mim}\right]\left[\mathrm{NTf}_{2}\right]$ at the air-water interface has been established and comprehensively studied for the first time. At large surface areas, BAM images show the existence of liquid domains in equilibrium with a vapor phase. On compression, the isotherms indicate an expanded film that can be gradually compressed down to relatively small surface areas.

At high surface pressure, the isotherms display a region of very high compressibility (plateau) extending to very low surface areas $\left(\sim 0.15 \mathrm{~nm}^{2}\right.$ molec $\left.^{-1}\right)$ only compatible with the formation of multilayers. Large hysteresis on expansion is observed. Along the plateau, BAM images revealed for the first time the formation of crystalline structures compatible with multilayering, which disappear on expansion.

MD simulations support the interpretations and provide molecular level insight to the experimental results. In particular, the simulation results show the existence of clusters at high surface areas, supporting the hypothesis of vaporliquid equilibrium. Structurally, the simulations indicate a checkerboard distribution of the charged groups in contact with water at all surface densities and liquid-like arrangement of the alkyl chains oriented towards the vapor phase. Additionally, the simulations show that the monolayer can be gradually compressed to form a very dense film. Finally, the simulations provide clear evidence that the compressed monolayer evolves to a trilayer. Further studies will include the direct characterization of the structure of the films using Grazing Incidence X-ray Difraction (GIXD).

P.M., E.J.M.F. and J.N.C.L. acknowledge funding from Fundação para a Ciência e a Tecnologia, Grant SFRH/BPD/81748/2011 and Grant Pest-OE/QUI/UI0100/2013. N.B. acknowledges funding from the DGA and ECE Paris.

\section{Notes and references}

1 A. Triolo, O. Russina, H. J. Bleif and E. Di Cola, J. Phys. Chem. B, 2007, 111, 4641.

2 J. Wang and G. A. Voth, J. Am. Chem. Soc., 2005, 127, 12192; J. N. Canongia Lopes and A. A. H. Pádua, J. Phys. Chem. B, 2006, 110, 3330.

3 X. Bai, L. Zheng, N. Li, B. Dong, B and H. Liu, Cryst. Growth Des., 2008, 8, 3840; X. Bai, X. Li and L. Zheng, Langmuir, 2010, 26, 12209.

4 I. Mukherjee, S. Mukherjee, B. Naskar, S. Ghosh and S. P. Moulik, J. Colloid Interface Sci., 2013, 395, 135.

5 W. Ye, S. He, L. Ding, Y. Yao, L. Wan, S. Miao and J. Xu, J. Phys. Chem. C, 2013, 117, 7026.

6 K. Shimizu, J. N. Canongia Lopes and A. M. P. S. Gonçalves da Silva, Langmuir 2015, 31, 8371.

7 L. Tamam, B. M. Ocko, H. Reichert and M. Deutsch, Phys. Rev. Lett., 2011, 106, 197801.

8 A. Downard, M. J. Earle, C. Hardacre, S. E. J. McMath, M. Nieuwenhuyzen and S. J. Teat, Chem. Mater., 2004, 16, 43.

9 J. K. Konieczny and B. Szefczyk, J. Phys. Chem. B, 2015, 119, 3795; M. Mezger, B. M. Ocko, H. Reichert and M. Deutsch, Proc. Natl. Acad. Sci. U.S.A., 2013, 110, 3733.

10 H. F. D. Almeida, M. G. Freire, A. M. Fernandes, J. A. Lopes da Silva, P. Morgado, K. Shimizu, E. J. M. Filipe, J. N. Canongia Lopes, L. M. N. B. F. Santos and J. A. P. Coutinho, Langmuir, 2014, 30, 6408.

11 W. Smith and T. R. Forester, The DL_POLY Package of Molecular Simulation Routines (v.2.2); Daresbury Laboratory: Warrington, U.K., 2006.

12 M. Praprotnik, D. Janežič and J. Mavri, J. Phys. Chem. A, 2004, 108, 11056.

13 J. N. Canongia Lopes, J. Deschamps and A. A. H. Pádua, J. Phys. Chem. B, 2004, 108, 2038; J. N. Canongia Lopes and A. A. H. Pádua, J. Phys. Chem. B, 2004, 108, 16893.

14 W. L. Jorgensen, D. S. Maxwell and J. Tirado-Rives, J. Am. Chem. Soc., 1996, 118, 11225.

15 L. Martínez, R. Andrade, E. G. Birgin and J. M. Martínez, J. Comput. Chem., 2009, 30, 2157. 